\title{
Pre-microRNA binding aminoglycosides and antitumor drugs as inhibitors of Dicer catalyzed microRNA processing
}

\author{
Mohitosh Maiti, Koen Nauwelaerts, Piet Herdewijn* \\ Laboratory of Medicinal Chemistry, Rega Institute for Medical Research, Katholieke Universiteit Leuven, \\ Minderbroedersstraat 10, 3000 Leuven, Belgium \\ ${ }^{*}$ Corresponding author. Tel: +32 16337387 Fax: +32 16337340 \\ E-mail address: Piet.Herdewijn@rega.kuleuven.be (P. Herdewijn)
}

\begin{abstract}
Over-expressions of miRNAs are being increasingly linked with many diseases including different types of cancer. In this study, the role of some known small molecular therapeutics has been investigated for their ability to bind with the pre-miRNA target (hsa-mir-155) and thereby to interfere with the Dicer catalyzed miRNA processing. Potential binding and inhibition effects have been demonstrated by some of these analogues. They can be used as leads for further development of potent small molecular miRNA-antagonists.
\end{abstract}

\section{Keywords: Dicer assay, micro RNA, Inhibitors, RNA recognition, structure-activity relationships}

MicroRNAs (miRNAs) are a class of recently discovered endogenous short ( 19-25 nt) noncoding RNAs that play a wide role in the post-transcriptional gene regulation. ${ }^{1-3}$ After being incorporated into the RNA-induced silencing complex (RISC), they regulate gene expression by base pairing with the complementary mRNAs, thereby blocking translation and/or affecting the mRNA stability. ${ }^{4}$ They are found to be involved in a variety of cellular physiological processes like development, differentiation, apoptosis, proliferation and metabolism. It is reported that an aberrant expression of certain miRNAs are also linked with different human diseases including many types of cancer. ${ }^{5-8}$

Traditionally, for the miRNA functional studies and for therapeutic intervention, oligonucleotide based gene therapy approaches like synthetic miRNA, antagomir and miRNA sponge/decoy are used. $^{9-12}$ However, they suffer from some limitations like cellular delivery, inappropriate biodistribution and chemical instability. ${ }^{13}$ In recent years an alternative approach based on small molecular chemical biology has been followed. ${ }^{14-18}$ This means that small molecules may also bind to miRNA and can influence its function. Indeed, in the final step of miRNA biogenesis, most of the mature miRNAs are formed in the cytoplasm by the Dicer-catalyzed processing (Figure 1) of their corresponding inactive pre-miRNA hairpin precursors. ${ }^{19-21}$ This step has 
previously been proposed as a suitable target for inhibitors design ${ }^{22-24}$ and recently, high affinity synthetic small molecule ligands have been described to bind with pre-miRNA. ${ }^{25,}{ }^{26}$ An in vitro fluorescence-labeled pre-miRNA based Dicer assay has been developed ${ }^{22,}{ }^{23}$ for screening small molecule inhibitors. In this work, we have explored whether inhibition of Dicer could be one of the mechanisms of action for established antitumor and antibacterial agents and if some known RNA binders could be used as leads to find new pre-miRNA inhibitors. Therefore, we have screened several different classes of known small molecules which are currently used in therapy, including some experimental small molecules for both evaluation of their binding properties to pre-hsa-mir-155 and their ability to inhibit Dicer-catalyzed miRNA maturation (Figure 1). In particular, antibacterial agents (Tetracyclines and Aminoglycosides), anticancer chemotherapeutics (Actinomycin D, Bleomycin, Daunorubicin and Doxorubicin) and some DNA/RNA intercalating compounds that are commonly used as fluorescent probes (Proflavine, DAPI, Ethidium and Hoechst 33258) have been evaluated. Some of these agents are known to exert their therapeutic effect by binding with the ribosomal RNA or DNA, thereby interfering with the nucleic acid metabolism. The antibacterial agents target bacterial ribosome (rRNAs) and interfere with translation; anti-cancer agents target DNA and thereby inhibiting function of Topoisomerases and RNA polymerases which are essential for normal replication and transcription. $^{27-29}$ In this study mir-155 was chosen as a target, since it was shown to have a pivotal role in the normal immune function ${ }^{30}$ and over-expression of this particular miRNA alone causes cancer in mice and thus behaves as an oncomir ${ }^{31}$.

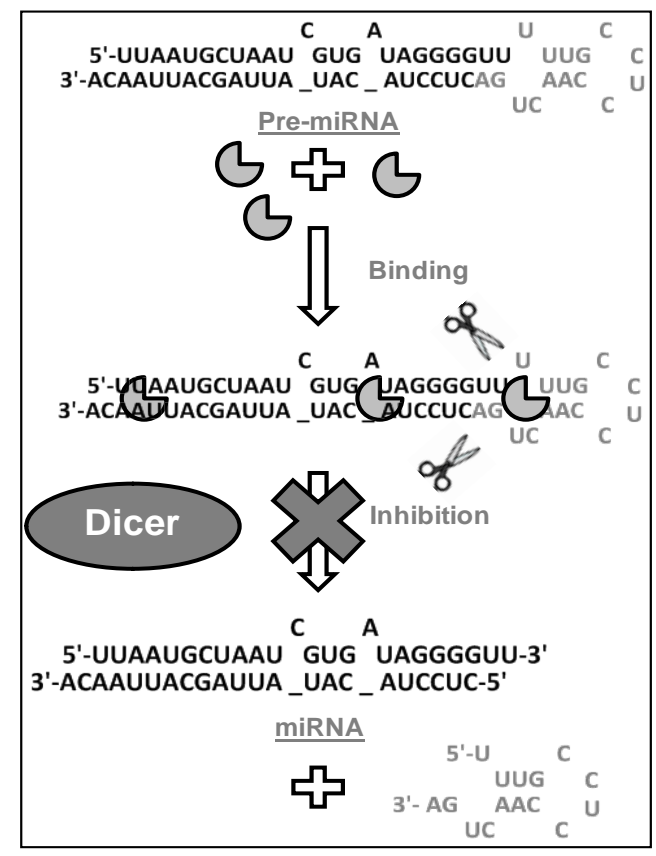


Figure 1. Schematic diagram depicting the Dicer catalyzed processing of pre-miRNA to mature miRNA duplex and inhibition of this reaction due to small molecule binding with the pre-miRNA substrate. Pre-hsa-mir-155 and mature miRNA duplex are shown with their secondary structure.

High-throughput screening of small molecules for pre-miRNA binding was performed by measuring the fluorescence intensity. For fluorescent ligands (ethidium and Hoechst), a direct binding experiment was performed by monitoring the intensity enhancement due to its binding with the pre-miRNA. For screening non-fluorescent ligands (aminoglycosides), an indirect binding assay (fluorescent intercalator displacement assay using Ethidium as reporter molecule, FID assay) ${ }^{32}$ was performed by monitoring the decrease of fluorescence intensity due to the displacement of pre-bound Ethidium from pre-miRNA target by the ligand. Initially, all ligands were screened at $0.5 \mathrm{mM}$ concentration. For some selected representative ligands, dose response assays were performed to determine the apparent dissociation constant $\left(K_{\mathrm{d}}\right)$ at room temperature (Figure 2A). Ethidium and Hoechst bind to the pre-miRNA target with a $K_{\mathrm{d}}$ of $5 \mu \mathrm{M}$ and $14 \mu \mathrm{M}$ respectively. Among the 10 aminoglycoside antibiotics screened, 5 compounds (see Table S1 in the supplementary information for a list of compounds) showed moderate affinity ( $\mu \mathrm{M} K_{\mathrm{d}}$ ). Framycetin and Kanamycin B showed relatively strong binding $\left(K_{d}=6 \mu \mathrm{M}\right)$, Neomycin moderate $\left(K_{\mathrm{d}}=11 \mu \mathrm{M}\right)$, and Kanamycin A showed weak binding $\left(K_{\mathrm{d}}=141 \mu \mathrm{M}\right)$. These binding affinity data correlate well with previously reported affinity data ${ }^{24}$ for aminoglycoside binding (non-specific) with other RNA targets. Some Tetracyclines (see Table S1 in the supplementary information) with sufficient aqueous solubility were also screened, but none of them were found to bind with the pre-miRNA target.
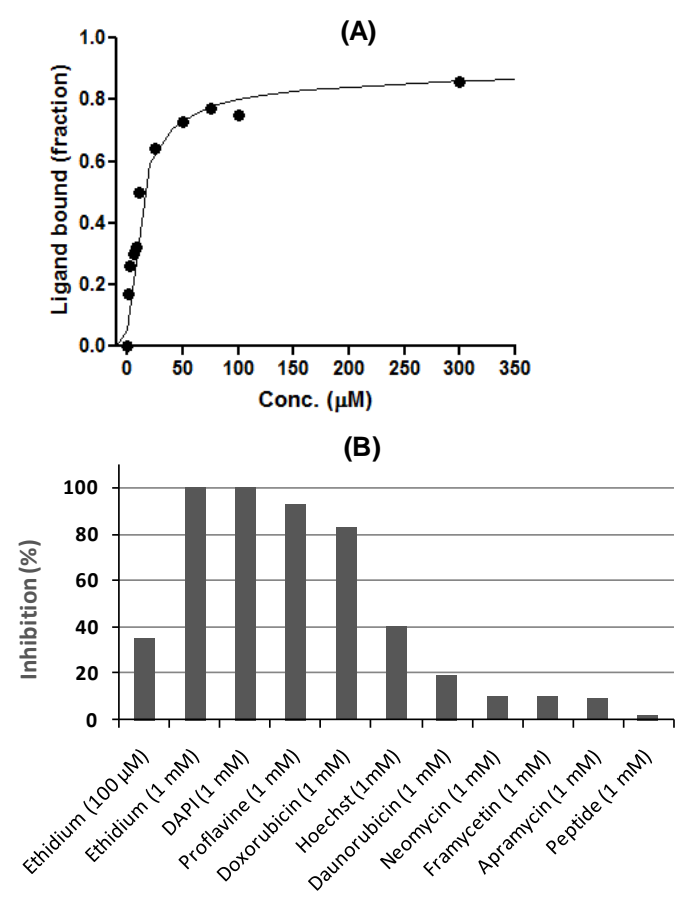
Figure 2. A) Representative hyperbolic binding curve (shown for Neomycin), B) Inhibition profile of various ligands for interfering with the Dicer-catalyzed pre-miRNA processing. Ligand concentrations are provided within parentheses. The peptide (linear 'anti-Dicer peptide') sequence (Ac-NH-AKPYSQRRKTSG-CONH ${ }_{2}$ ) used is based on ref. 22.

It was previously shown that binding of intercalators with RNA may lead to structural alternation of RNA targets. ${ }^{24}$ Therefore, FID binding assay may identify false positive hits representing binding of the small molecules to the RNA-intercalator complex rather than binding to the true RNA target. In order to confirm the binding of aminoglycosides to native pre-miRNA and to qualitatively validate the dissociation constants determined by FID assay, we have also performed a direct binding study by measuring the thermal melting temperature $\left(T_{\mathrm{m}}\right)$ of premiRNA target. An increase of $T_{\mathrm{m}}$ was observed due to the binding interaction of aminoglycosides to the pre-miRNA target. From the thermal melting data (Table 1) it is apparent that aminoglycosides do bind to the pre-miRNA target and also demonstrate a dose response in the concentration range of FID determined dissociation constant.

Table 1. Thermal melting temperatures of pre-hsa-mi-155 target alone and in presence of different concentrations of various aminoglycoside ligands.

\begin{tabular}{ccc}
\hline Aminoglycoside & Ligand Conc. $(\mu \mathrm{M})$ & $T_{\mathrm{m}}\left({ }^{\circ} \mathrm{C}\right)$ \\
\hline Pre-miRNA & 0 & 48 \\
\hline + Framycetin & 2 & 50 \\
& 10 & $>70$ \\
\hline + Neomycin & 12 & $>70$ \\
\hline \multirow{2}{*}{+ Kanamycin A } & 2 & 48 \\
& 12 & $>70$ \\
\hline
\end{tabular}

Different classes of small molecules (including all the compounds that were identified to bind with the pre-hsa-mir-155 by FID assay) were evaluated (at a 1mM concentration) for the inhibition of Dicer-catalyzed pre-miRNA processing (Figure 2B). Inhibition assay was performed with a $5^{\prime}\left({ }^{33} \mathrm{P}\right)$-end labeled pre-miRNA substrate. The products of the Dicer-catalyzed reactions were analyzed by denaturing polyacrylamide gel electrophoresis (PAGE) and were visualized by phosphorimaging (Figure 3 \& S1-3). Generally, intercalating compounds with one or more positive charge(s) showed high level of inhibition (Figure 3 \& S1-2). Ethidium (identified to bind with pre-hsa-mir-155) and DAPI showed complete inhibition (100\%), 
Proflavine (93 \%) and Doxorubicin (83 \%) also have high inhibition efficiency, while Hoechst 33258 (40 \%) and Daunorubicin (19\%) were found to be moderate to weak inhibitors at $1 \mathrm{mM}$ concentration (Figure 2B). Quinacrine and Berberine show almost no inhibition (Figure S1). Although aminoglycoside antibiotics were determined to bind (possibly by groove-binding) with this pre-miRNA target with $\mu \mathrm{M}$ affinity, only Neomycin, Framycetin and Apramycin demonstrate very weak (10\%) inhibition (Figure 3 \& S3) of Dicer cleavage. Linear anti-Dicer peptide, ${ }^{22}$ which was previously shown to inhibit pre-miRNA processing, was found to be ineffective even at $1 \mathrm{mM}$ concentration. Polypeptide (Actinomycin D) and Glycopeptide (Bleomycin, Vancomycin) antibiotics were also found to be ineffective (Figure S2 \& S3). Interestingly in the Dicer assay it was observed that pre-miRNA processing not only generates specific miRNA product but also degradation products corresponding to non-specific cuts. All the inhibitors identified in the screening are non-specific binders and inhibitors since both specific and non-specific Dicer cuts were simultaneously inhibited (Figure 3 \& S1-2).

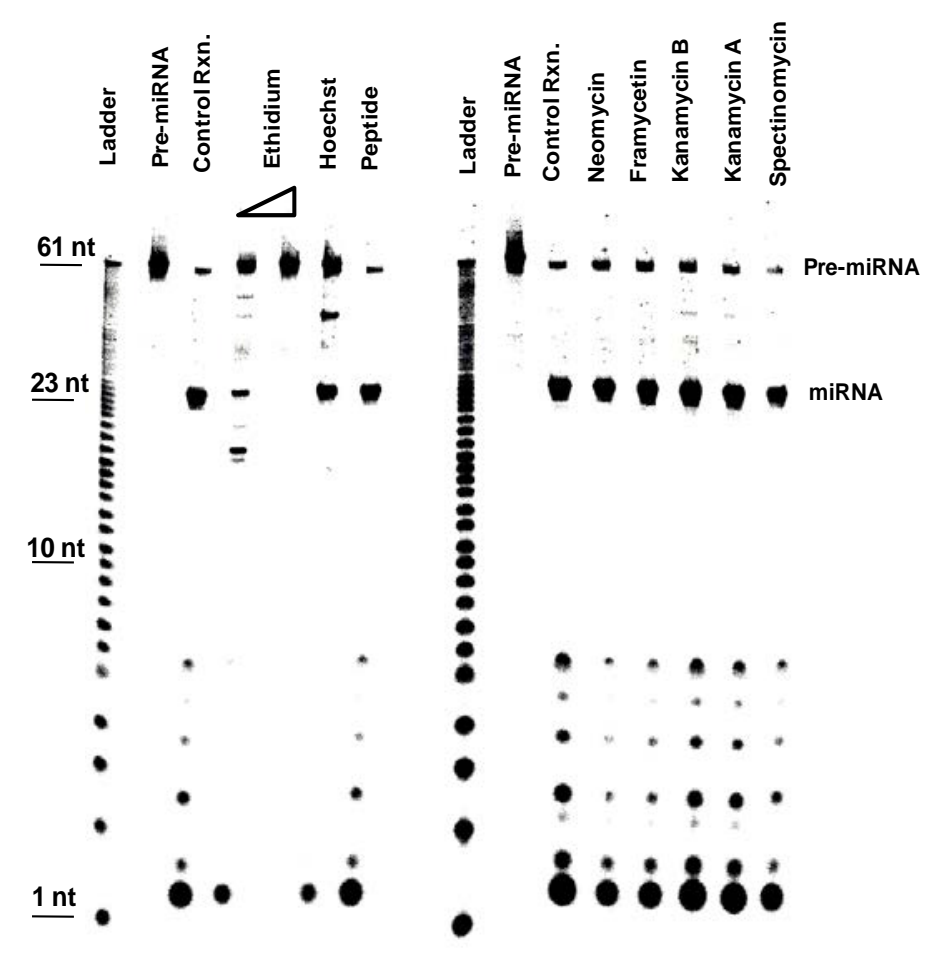

Figure 3. Gel image displaying various products formed after control and inhibition reactions for the Dicercatalyzed pre-miRNA processing. For Ethidium two different concentrations were used (Left: $100 \mu \mathrm{M}$ and Right: 1 $\mathrm{mM}$ ), whilst all other ligands were screened at $1 \mathrm{mM}$ concentration.

In this study it is shown that some aminoglycosides bind to pre-mir-155 but are not effective in inhibiting miRNA maturation. However, the binding of aminoglycosides to pre-miRNAs or miRNA duplexes has the potential to interfere with other step(s) in the miRNA pathway. It will 
be interesting to evaluate aminoglycosides in the cellular assay systems for their ability to influence the miRNA pathways and this may explain any possible role in the side effects of this class of antibiotics. On the other hand, some anticancer chemotherapeutics (Daunorubicin and Doxorubicin) including other intercalating agents demonstrated moderate affinity binding to premiRNA and exert non-specific inhibition of the Dicer catalyzed pre-miRNA maturation. These results point to a potential role in the pre-miRNA processing as an additional mode of action of these anticancer agents. Additionally, it provides new lead compounds for identifying the high affinity ligands and inhibitors for regulating miRNA expression.

Finding the selective small molecular inhibitors for in vivo targeting of pre-miRNA will be extremely challenging, since a large number of miRNAs has similar stem-loop hairpin structure. $^{22,33}$ Although, our initial screening identified small molecular ligands for pre-miRNA binding and that inhibit Dicer catalyzed miRNA maturation, none of these ligands are high affinity specific ligands for pre-miRNA. Aminoglycosides were previously shown to be notoriously promiscuous in binding with other small RNA targets which have inherent structural plasticity. ${ }^{24}$ It will therefore be necessary to derivatize aminoglycosides by chemical conjugation with intercalators or other types of scaffolds to improve specificity and potency. ${ }^{25,}{ }^{34}$ Intercalators are shown to have better Dicer inhibitory property, while aminoglycosides have better RNA recognition property. Therefore, hybrids between these two classes might serve as future potential inhibitors. Specific structural feature of individual pre-miRNA secondary structure can be considered for designing the hybrid efficient ligands.

\section{Acknowledgments}

This work was financed by K. U. Leuven grant (GOA). M.M. is grateful to K. U. Leuven (IRO) for doctoral fellowship. We are thankful to Prof. Ann Van Schepdael for generous gift of antibiotic compounds. We thank Dr. Anne Giraut and Guy Schepers for technical support, Munmun Maiti and Chantal Biernaux for editorial help.

\section{Supplementary data}

\section{References}

1. $\quad$ Lee, R. C.; Feinbaum, R. L.; Ambros, V. Cell 1993, 75, 843.

2. Ambros, V. Nature 2004, 431, 350.

3. He, L.; Hannon, G. J. Nat. Rev. Genet. 2004, 5, 522.

4. $\quad$ Bartel, D. P. Cell 2004, 116, 281.

5. $\quad$ Gregory, R. I.; Shiekhattar, R. Cancer Res. 2005, 65, 3509.

6. Wiemer, E. A. Eur. J. Cancer 2007, 43, 1529.

7. Couzin, J. Science 2008, 319, 1782.

8. Garofalo, M.; Croce, C. M. Annu. Rev. Pharmacol. Toxicol. 2011, 51, 25.

9. $\quad$ Meister, G.; Landthaler, M.; Dorsett, Y.; Tuschl, T. RNA 2004, 10, 544.

10. Davis, S.; Lollo, B.; Freier, S.; Esau, C. Nucleic Acids Res. 2006, 34, 2294. 
11. Hammond, S. M. Trends Mol. Med. 2006, 12, 99.

12. Garzon, R.; Marcucci, G.; Croce, C. M. Nat. Rev. Drug Discov. 2010, 9, 775.

13. Xu, L.; Anchordoquy, T. J. Pharm. Sci. 2011, 100, 38.

14. Gumireddy, K.; Young, D. D.; Xiong, X.; Hogenesch, J. B.; Huang, Q.; Deiters, A. Angew. Chem. Int. Ed. 2008, 47, 7482.

15. Watashi, K.; Yeung, M. L.; Starost, M. F.; Hosmane, R. S.; Jeang, K. T. J. Biol. Chem. $2010,285,24707$.

16. Young, D. D.; Connelly, C. M.; Grohmann, C.; Deiters, A. J. Am. Chem. Soc. 2010, $132,7976$.

17. Deiters, A. AAPS J. 2010, 12, 51.

18. Li, Y.; He, C.; Jin, P. Chem. Biol. 2010, 17, 584.

19. Elbashir, S. M.; Lendeckel, W.; Tuschl, T. Genes Dev. 2001, 15, 188.

20. Provost, P.; Dishart, D.; Doucet, J.; Frendewey, D.; Samuelsson, B.; Radmark, O. EMBO J. $2002,21,5864$.

21. Bosse, G. D.; Simard, M. J. Cell Res. 2010, 20, 735.

22. Davies, B. P.; Arenz, C. Angew. Chem. Int. Ed. 2006, 45, 5550.

23. Davies, B. P.; Arenz, C. Bioorg. Med. Chem. 2007, 16, 49.

24. Thomas, J. R.; Hergenrother, P. J. Chem. Rev. 2008, 108, 1171.

25. Krishnamurthy, M.; Simon, K.; Orendt, A. M.; Beal, P. A. Angew. Chem. Int. Ed. 2007, 46, 7044.

26. Chirayil, S.; Chirayil, R.; Luebke, K. J. Nucleic Acids Res. 2009, 37, 5486.

27. Kotra, L. P.; Haddad, J.; Mobashery, S. Antimicrob. Agents Chemother. 2000, 44, 3249.

28. $\quad$ Nitiss, J. L. Nat. Rev. Cancer 2009, 9, 338.

29. Sobell, H. M. Proc. Natl. Acad. Sci. U.S.A. 1985, 82, 5328.

30. Rodriguez, A.; Vigorito, E.; Clare, S.; Warren, M. V.; Couttet, P.; Soond, D. R.; van Dongen, S.; Grocock, R. J.; Das, P. P.; Miska, E. A.; Vetrie, D.; Okkenhaug, K.; Enright, A. J.; Dougan, G.; Turner, M.; Bradley, A. Science 2007, 316, 608.

31. Costinean, S.; Zanesi, N.; Pekarsky, Y.; Tili, E.; Volinia, S.; Heerema, N.; Croce, C. M. Proc. Natl. Acad. Sci. U.S.A. 2006, 103, 7024.

32. Chaltin, P.; Borgions, F.; Van Aerschot, A.; Herdewijn, P. Bioorg. Med. Chem. Lett. 2003, $13,47$.

33. Gallego, J.; Varani, G. Acc. Chem. Res. 2001, 34, 836.

34. Shaw, N. N.; Xi, H.; Arya, D. P. Bioorg. Med. Chem. Lett. 2008, 18, 4142.

\section{Figure for Graphical Abstract}

\section{Regulating over-expressed miRNAs}

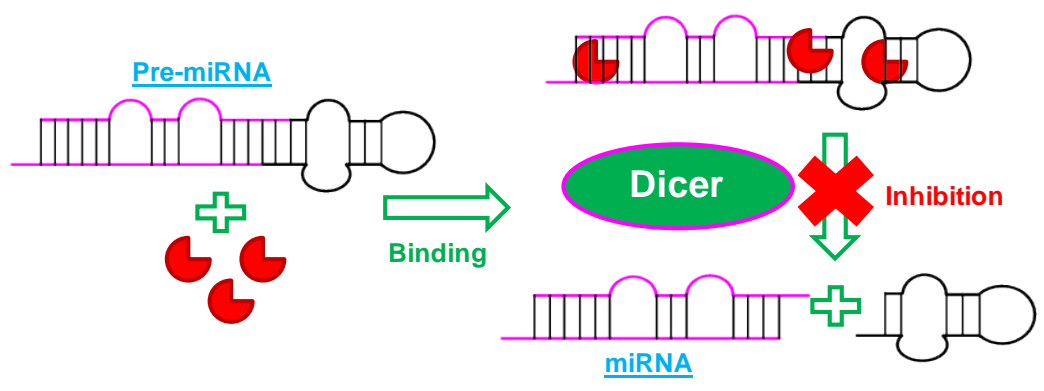




\title{
Supplementary Information
}

\section{Screening for pre-microRNA binding small molecules as inhibitors of the Dicer catalyzed pre-microRNA processing}

\author{
Mohitosh Maiti, Koen Nauwelaerts, Piet Herdewijn*
}

Laboratory of Medicinal Chemistry, Rega Institute for Medical Research, Katholieke Universiteit Leuven, Minderbroedersstraat 10, 3000 Leuven, Belgium

*Corresponding author. Fax: +32 16 337340, E-mail: Piet.Herdewijn@rega.kuleuven.be

Table S1. List of different class of compounds that were screened in this study along with their experimental binding affinities.

\begin{tabular}{|c|c|c|}
\hline Compound family & Compound name & Binding affinity \\
\hline \multirow{2}{*}{ Intercalators } & Ethidium bromide & Strong $\left(K_{\mathrm{d}}=5 \mu \mathrm{M}\right)$ \\
\hline & Hoechst 33258 & Moderate $\left(K_{\mathrm{d}}=14 \mu \mathrm{M}\right)$ \\
\hline \multirow{8}{*}{ Aminoglycosides } & Framycetin & Strong $\left(K_{\mathrm{d}}=6 \mu \mathrm{M}\right)$ \\
\hline & Kanamycin B & Strong $\left(K_{\mathrm{d}}=6 \mu \mathrm{M}\right)$ \\
\hline & Neomycin & Moderate $\left(K_{\mathrm{d}}=11 \mu \mathrm{M}\right)$ \\
\hline & Kanamycin A & Weak $\left(K_{\mathrm{d}}=141 \mu \mathrm{M}\right)$ \\
\hline & Spectinomycin & Weak $\left(K_{\mathrm{d}}>100 \mu \mathrm{M}\right)$ \\
\hline & Amikacin & ," \\
\hline & Dihydrostreptomycin & ,' \\
\hline & Gentamycin & ," \\
\hline
\end{tabular}




\begin{tabular}{|c|c|c|}
\hline & Netilmycin & , \\
\hline & Tobramycin & ” \\
\hline \multirow{10}{*}{ Tetracyclines } & Tetracycline .HCl & Non binding \\
\hline & 4-Epitetracycline. $\mathrm{HCl}$ & , \\
\hline & Anhydrotetracycline. $\mathrm{HCl}$ & ", \\
\hline & 4-Epianhydrotetracycline. $\mathrm{HCl}$ & ", \\
\hline & 4-Epichlortetracycline . $\mathrm{HCl}$ & ” \\
\hline & 4-Epianhydrochlortetracycline . $\mathrm{HCl}$ & , \\
\hline & Demethylchlortetracycline. $\mathrm{HCl}$ & , \\
\hline & Doxycycline hyclate & , \\
\hline & Minocycline. $\mathrm{HCl}$ & , \\
\hline & Methacycline .HCl & , \\
\hline
\end{tabular}

\section{Experimental Section}

Materials- PAGE purified 61 nt pre-miRNA (hsa-mir-155 hairpin with 2 nt 3'-overhang) oligo was purchased from Eurogentec S.A., Belgium, and used as such to prepare stock solutions (50 $\mu \mathrm{M}$ ) in RNase-free water. Recombinant human Dicer enzyme was purchased from Invitrogen (as part of BLOCK-iT ${ }^{\mathrm{TM}}$ Dicer RNAi Kit) and used with its proprietary buffer solution. Purified (Biochemistry grade) 12-mer anti-Dicer peptide was purchased from Eurogentec S.A. and used as such to prepare aqueous stock solutions $(10 \mathrm{mM})$. Some of the small molecule ligands were purchased from Sigma-Aldrich. Aqueous stock solutions ( $10 \mathrm{mM})$ of all ligands were prepared by measuring dry weight of the corresponding compounds.

Fluorescent intercalator displacement (FID) assay- Wells of Costar black 96-well plates were loaded with $2 \mu \mathrm{L}$ of pre-miRNA solution $(50 \mu \mathrm{M}), 2 \mu \mathrm{L}(0.75 \mathrm{mM})$ of Ethidium bromide (EtBr) solution (EtBr : Base pair 1:2) and a varying volume (0.2-10 $\mu \mathrm{L}$ ) of ligand solutions, to obtain the necessary concentrations (for $K_{\mathrm{d}}$ determination). Generally, all ligands were initially screened at $500 \mu \mathrm{M}$ for determination of the relative binding affinity. An appropriate volume of 
Tris-HCl buffer (10 mM Tris, $10 \mathrm{mM} \mathrm{NaCl}, \mathrm{pH}$ 7.4) was added to obtain a total volume of 100 $\mu \mathrm{L}$ per well. Before adding in the wells, the Pre-miRNA solution was briefly heated to $70{ }^{\circ} \mathrm{C}$ for $5 \mathrm{~min}$ and then snap cooled in ice in order to promote hairpin formation. Initially the mixtures of RNA, EtBr and buffer solution were incubated for $10 \mathrm{~min}$ at room temperature (RT), and then ligand solutions were mixed and incubated for another $30 \mathrm{~min}$ at RT before measurement. Each well of a 96-well plate was measured for fluorescence intensity (at RT) in a Tecan infinite M200 reader, with $546 \pm 9 \mathrm{~nm}$ as excitation wavelength and $595 \pm 20 \mathrm{~nm}$ as emission detection wavelength. Two control wells were used in the 96-well plate (no ligand $=100 \%$ and no RNA = $0 \%$ fluorescence). Generally two to three sets of measurements were performed to calculate average intensity. Approximately the apparent experimental binding constants (Kds, without considering the stoichiometry of the binding equilibrium) for different ligands were determined from the hyperbolic binding isotherms (\% bound vs. Ligand concentration plot).

Thermal melting $\left(\boldsymbol{T}_{\mathbf{m}}\right)$ study- Pre-miRNA was dissolved in buffer solution (10 mM Tris, $10 \mathrm{mM}$ $\mathrm{NaCl}, \mathrm{pH}$ 7.4). For each ligand, 2-4 samples were prepared in buffer solution with RNA and ligand concentrations of $1 \mu \mathrm{M}$ and $0,2,10,12$, and $112 \mu \mathrm{M}$ respectively. Cuvettes with $1 \mathrm{~cm}$ path length were used. Melting curves were obtained by using a Varian Cary 100 BIO spectrometer. Temperature control and data acquisition were carried out automatically by using Cary WinUV software. The samples were heated from 15 to $85{ }^{\circ} \mathrm{C}$ at a rate of $0.2{ }^{\circ} \mathrm{C} / \mathrm{min}$, and were cooled at the same speed. Melting temperatures were determined by plotting the firstderivative of the absorbance (at $260 \mathrm{~nm}$ ) as a function of temperature.

Inhibition assay of pre-miRNA maturation- Pre-miRNA was 5'-end labeled with ${ }^{33} \mathrm{P}$ phosphate group by using $\gamma^{33} \mathrm{P}$-ATP (Perkin-Elmer) and T4 polynucleotide kinase (New England Biolabs) according to the standard procedure. The labeled RNA was purified by using Microspin G-25 spin column (GE Healthcare). The labeled pre-miRNA was used (160 nM) in a typical (as recommended by Invitrogen) $10 \mu \mathrm{L}$ Dicer control or inhibition reaction with Dicer concentration of $0.1 \mathrm{U} / \mu \mathrm{L}$. For inhibition reactions, 1 (and 0.1 ) $\mathrm{mM}$ concentrations of inhibitors were used. Samples were incubated at $37{ }^{\circ} \mathrm{C}$ for $1 \mathrm{~h}$ and then quenched by addition of $10 \mu \mathrm{L}$ quenching (loading) buffer containing $80 \%$ formamide, $0.05 \%$ bromophenol blue, $0.05 \%$ xylene cyanol and $50 \mathrm{~mm}$ EDTA. Pre-miRNA hydrolysis ladder was prepared by incubating labeled RNA solution (10 $\mu \mathrm{L}, 160 \mathrm{nM})$ in $50 \mathrm{mM} \mathrm{NaHCO}_{3}$ buffer (pH 9.0) at $95{ }^{\circ} \mathrm{C}$ for $10 \mathrm{~min}$ and then cooling in ice for $10 \mathrm{~min}$. Reaction samples $(10 \mu \mathrm{L})$ were analysed by polyacrylamide gel electrophoresis (20\% PAGE, 19:1 = mono:bis) for $5 \mathrm{~h}$ at $20 \mathrm{~W}$ on $30 \mathrm{~cm} \times 40 \mathrm{~cm} \times 0.4 \mathrm{~mm}$ denaturing gel (containing $0.4 \mathrm{~g} / \mathrm{mL}$ Urea) using Tris-borate running buffer (100 mm Tris-borate, $2.5 \mathrm{~mm}$ EDTA, pH 8.3). Products were visualized by phosphorimaging. The amount of radioactivity in the bands corresponding to the products of Dicer reaction (and \% inhibition) was determined by the Perkin-Elmer Cyclone device and Optiquant image analysis software. 


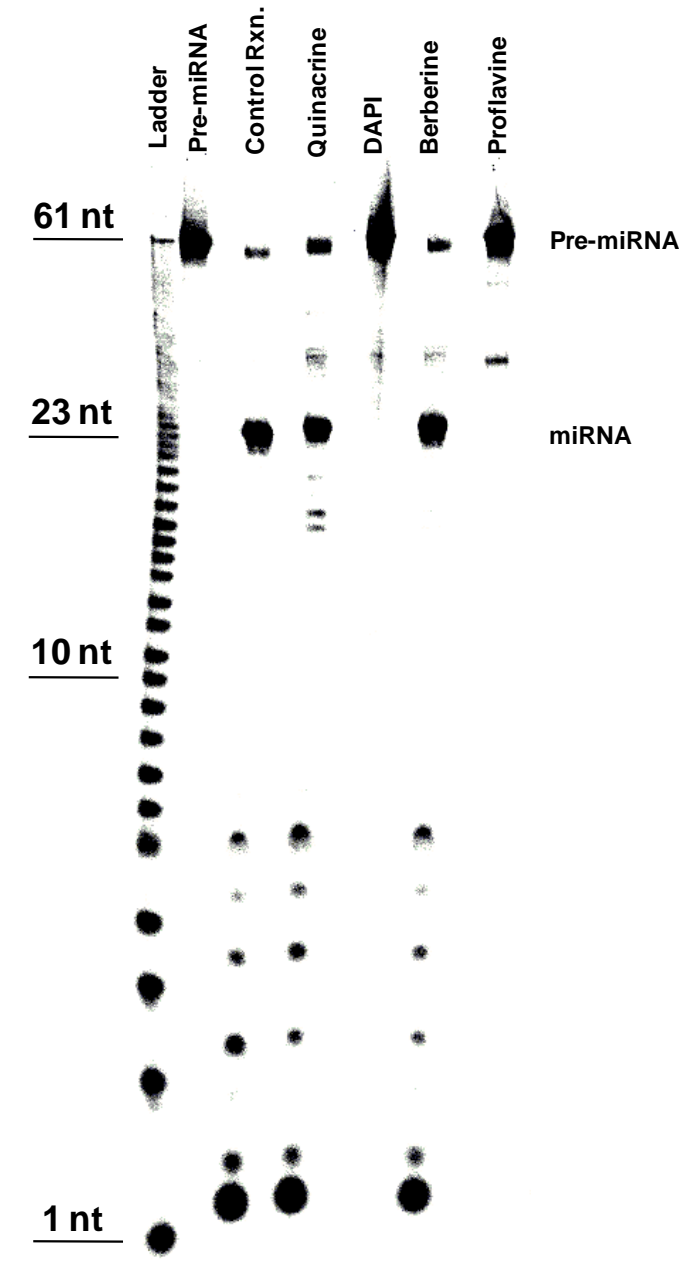

Figure S1
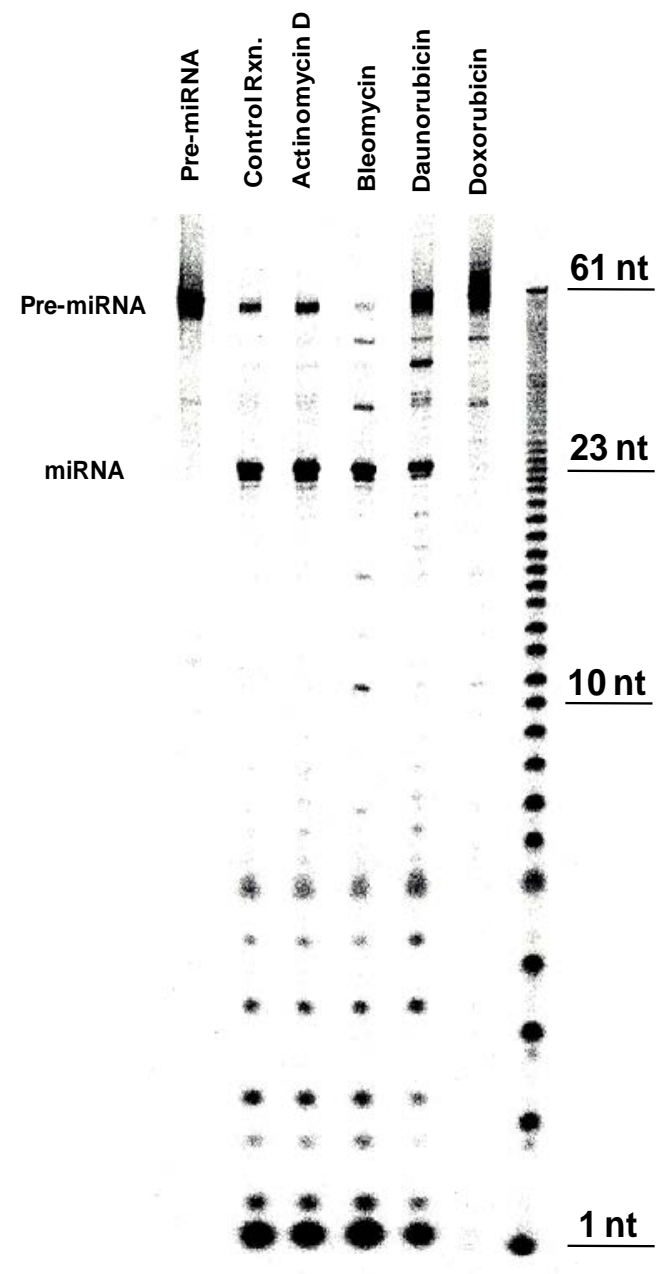

Figure S2 


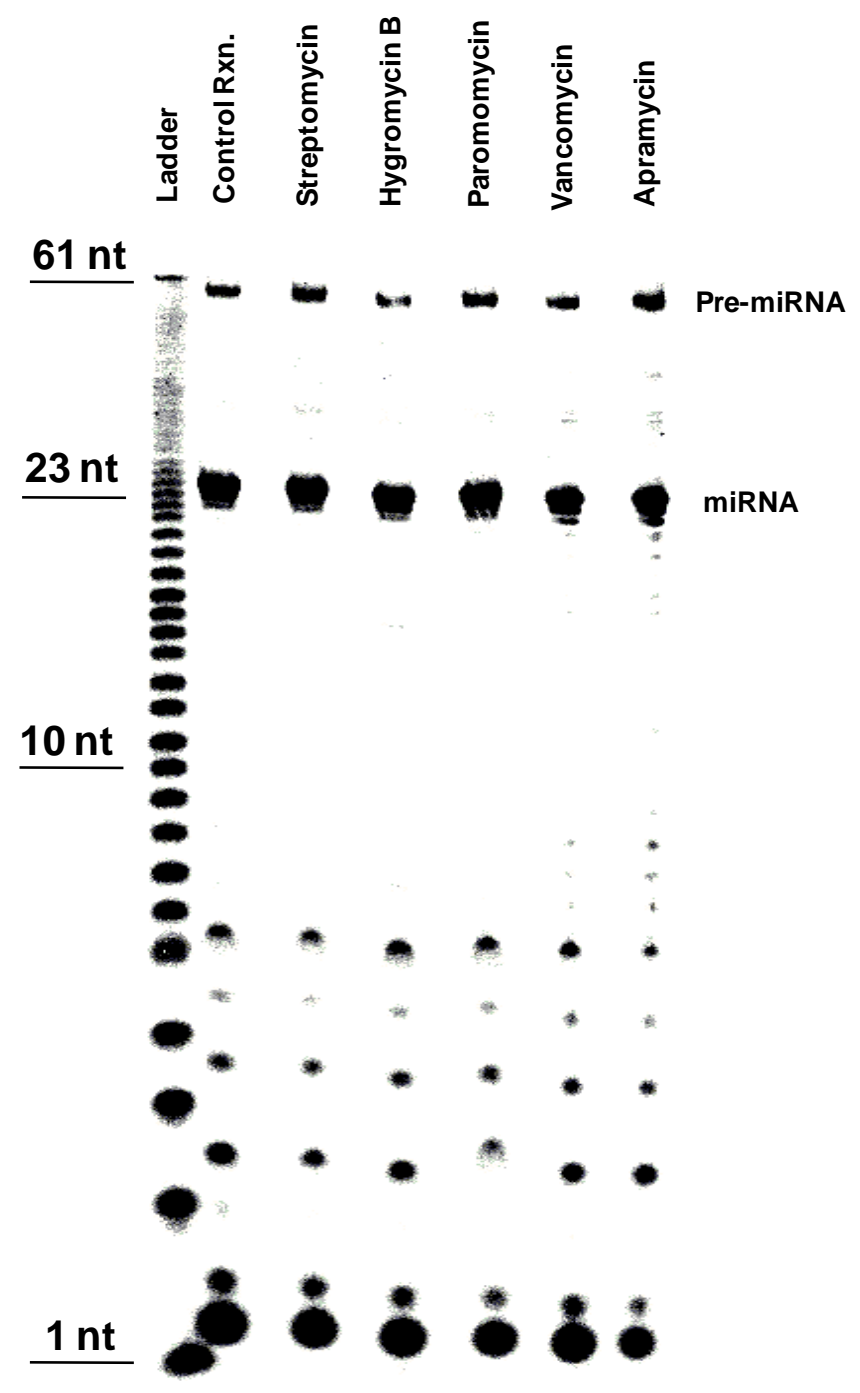

Figure S3

Figure S1-S3: Gel image displaying various products formed after control and inhibition reactions for Dicer catalyzed pre-miRNA processing. All ligands were screened at a $1 \mathrm{mM}$ concentration. 